\title{
Oridonin enhances antitumor activity of gemcitabine in pancreatic cancer through MAPK-p38 signaling pathway
}

\author{
HE-QI BU ${ }^{1 *}$, JIANG LUO $^{1 *}$, HUI CHEN ${ }^{1 *}$, JIAN-HONG ZHANG ${ }^{1}$, HONG-HAI LI ${ }^{1}$, \\ HONG-CHUN GUO ${ }^{1}$, ZHAO-HONG WANG ${ }^{1}$ and SHENG-ZHANG LIN ${ }^{1,2}$ \\ ${ }^{1}$ Department of Hepatobiliary-Pancreatic Surgery, The Second Affiliated Hospital of \\ Wenzhou Medical College, Wenzhou; ${ }^{2}$ Department of Hepatobiliary-Pancreatic Surgery, \\ The First Affiliated Hospital, Medical College, Zhejiang University, Hangzhou, Zhejiang, P.R. China
}

Received March 10, 2012; Accepted April 24, 2012

DOI: 10.3892/ijo.2012.1519

\begin{abstract}
Gemcitabine is currently the best treatment available for pancreatic cancer $(\mathrm{PaCa})$; however, patients with the disease develop resistance to the drug over time. Agents that can either enhance the effects of gemcitabine or overcome chemoresistance to the drug are required for the treatment of $\mathrm{PaCa}$. Oridonin is one such agent which is safe and multitargeted, and has been linked with the suppression of survival, proliferation, invasion and angiogenesis of cancer. In this study, we investigated whether oridonin could sensitize $\mathrm{PaCa}$ to gemcitabine in vitro and in vivo. In vitro, oridonin inhibited the proliferation of the $\mathrm{PaCa}$ cell line, $\mathrm{BxPC}-3$, potentiated the apoptosis induced by gemcitabine, induced G1 cell cycle arrest and activated p38 and p53; these results were significant when oridonin was combined with gemcitabine. In vivo, we found that oridonin significantly suppressed tumor growth and this effect was further enhanced by gemcitabine $(\mathrm{P}<0.05)$. Tumors from nude mice injected with $\mathrm{BxPC}-3$ PaCa cells and treated with a combination of oridonin and gemcitabine showed a significant upregulation in p38 and p53 activation $(\mathrm{P}<0.05$ vs. control, $\mathrm{P}<0.05$ vs. gemcitabine or oridonin alone). Taken together, our results demonstrate that oridonin can potentiate the effects of gemcitabine in $\mathrm{PaCa}$ through the mitogen-activated protein kinase (MAPK)-p38 signaling pathway, which is dependent on p53 activation.
\end{abstract}

\section{Introduction}

Pancreatic carcinoma $(\mathrm{PaCa})$ is one of the most lethal solid malignancies and the fourth leading cause of cancer-related

Correspondence to: Dr Sheng-Zhang Lin, Department of Hepatobiliary-Pancreatic Surgery, The Second Affiliated Hospital of Wenzhou Medical College, No. 109 Xue-yuan Road, Wenzhou, Zhejiang 325027, P.R. China

E-mail:wzf21sz@163.com

*Contributed equally

Key words: oridonin, gemcitabine, p53, p38, pancreatic cancer mortality in North America, where over 38,000 cases are diagnosed annually, with a similar number of patients dying from the disease $(1,2)$. Pancreatic ductal adenocarcinoma (PDAC) accounts for more than $95 \%$ of $\mathrm{PaCa}$ (3). It is characterized by a rapid disease progression and absence of specific symptoms, largely precluding an early diagnosis and curative treatment, and is associated with a very poor prognosis (4). Despite progress in chemotherapy, radiation therapy, immunotherapy and surgery over the past several years, the overall 5-year relative survival rate is less than 5\% (5). Gemcitabine has been the standard systemic therapy for the palliative treatment of $\mathrm{PaCa}$ over the last decade, although the 1-year survival rates ranging at approximately $18 \%$ remain unsatisfactory (6-8). The comparably low rate of sideeffects of gemcitabine treatment makes additional treatment options feasible (9) and a substantial number of potential drug combinations have been tested. However, no convincing results on clinically relevant improvements in the quality of life and survival have been found. Thus, it is impartial to state that there are still no evidence-based treatment options for gemcitabinerefractory advanced $\mathrm{PaCa}$, and effective additional agents to the first-line gemcitabine treatment have not yet to be found (10). Therefore, it is imperative to provide an effective means by which to enhance the sensitivity of $\mathrm{PaCa}$ cells to gemcitabine in order to increase the curative effect of gemcitabine, and thus improve patient outcomes.

The concept of using a combination of agents for cancer chemoprevention has recently received much attention. Considerable evidence from laboratory studies suggests that combinations of chemopreventive agents may be more effective for the prevention of cancer than any single constituent. Recent studies show that the traditional Chinese medicine, curcumin (11), and drugs such as resveratrol (12), thymoquinone (13) and emodin (14-16) used in combination with gemcitabine can significantly inhibit malignant tumor cell proliferation.

Oridonin is a diterpenoid purified from Rabdosia rubescens and has been reported to exert various pharmacological and physiological effects, such as anti-inflammatory, antibacterial, and antitumor effects (17). As regards its antitumor activity, certain reports have demonstrated that oridonin exhibits remarkable inhibitory effects on hepatocellular carcinoma, human osteosarcoma cells, U937 human macrophage-like 
cells, A431 human epidermoid carcinoma cells, non-small cell lung cancers, acute promyelocytic leukemia, as well as glioblastoma multiforme (18-22), and others have also shown that oridonin has cytotoxic effects on various cancer cells, such as HeLa human cervical carcinoma, MCF-7 human breast adenocarcinoma, L929 murine fibrosarcoma and colorectal cancer cells (23-26). These functions have been identified through the regulation of tumor cell proliferation and apoptosis-related genes. Apoptosis can be triggered in many ways, and it is well known that many proteins, such as cysteine-dependent aspartate-specific proteases (caspase) family, the Bcl-2 family, the mitogen-activated protein kinase (MAPK) family, p53 and phosphoinositide 3-kinase (PI3K) signal transduction pathways play important roles in regulating the apoptotic process (27-29). MAPKs have been shown to phosphorylate p53 in response to a variety of stressful stimuli, leading to p53-mediated cellular responses, causing cell cycle arrest and apoptosis (30). Currently, the involvement of p38 and p53 in the attenuation of the antitumor effect of oridonin in combination with gemcitabine in the treatment of $\mathrm{PaCa}$ has been not reported. Whether oridonin can potentiate the effect of gemcitabine in $\mathrm{PaCa}$, also remains unknown.

Therefore, in this study, we investigated the effect of oridonin on the growth of human $\mathrm{PaCa}$ cells in culture and in a subcutaneous mouse model of $\mathrm{PaCa}$, and examined the effect of oridonin in combination with gemcitabine both in vitro and in vivo. We also investigated the role of $\mathrm{p} 38$ and $\mathrm{p} 53$ in the induction of apoptosis in the BxPC-3 human PaCa cell line. We demonstrate that oridonin can potentiate the therapeutic effects of gemcitabine against $\mathrm{PaCa}$ cells in vitro and in vivo. We show that the upregulation of p38 and p53 by oridonin is one of the mechanisms of the inhibition of tumor growth of $\mathrm{PaCa}$. Our results can lead to an improvement in the treatment of $\mathrm{PaCa}$.

\section{Materials and methods}

Chemicals and reagents. Oridonin was obtained from the Beijing Institute of Biological Products (Beijing, China). The purity of oridonin was measured by high-performance liquid chromatography (HPLC) and determined to be $99.4 \%$. Oridonin was dissolved in dimethyl sulfoxide (DMSO) to create a stock solution at a concentration of $10 \mathrm{mmol} / 1$ and stored at $-20^{\circ} \mathrm{C}$. The DMSO concentration was kept below $0.1 \%$ in all the cell cultures and did not exert any detectable effect on cell growth or cell death. Gemcitabine (Gemzar) from Eli Lilly was stored at $4^{\circ} \mathrm{C}$ and dissolved in sterile phosphate-buffered saline (PBS) at a concentration of $0.2 \mathrm{mmol} / \mathrm{l}$ on the day of use. Fetal bovine serum (FBS), trypsin-EDTA, Roswell Park Memorial Institute-1640 (RPMI-1640) and the Cell Counting kit-8 (CCK-8) were obtained from Gibco, the Annexin V-FITC/ PI apoptosis detection kit was from Biological Development Co, Ltd. Nanjing KGI, the RNA extraction kit was from Life Technologies Co., the cDNA first-strand synthesis kit was from Fermentas and the 2X Taq PCR MasterMix was from Tiangen. Ribonuclease A (RNase A), propidium iodide (PI) and DMSO were obtained from Sigma. Antibodies against p53, phosphorylated p53 (P-p53), p38, phosphorylated p38 (P-p38), $\beta$-actin and horseradish peroxidase (HRP)-conjugated secondary antibodies (goat-anti-rabbit and goat-anti-mouse) were purchased from Sigma.
Cell line and culture. The $\mathrm{PaCa}$ cell line, BxPC-3, was obtained from the American Type Culture Collection (ATCC; Manassas, VA, USA). All cells were cultured in RPMI-1640 medium supplemented with $10 \% \mathrm{FBS}, 100 \mathrm{U} / \mathrm{ml}$ penicillin and $100 \mu \mathrm{g} / \mathrm{ml}$ streptomycin. Cells were maintained at $37^{\circ} \mathrm{C}$ in a humidified atmosphere of $5 \% \mathrm{CO}_{2}$. The medium was changed every 2-3 days, and the cells were subcultured when confluency reached $70-80 \%$ by $0.25 \%$ trypsin at $37^{\circ} \mathrm{C}$.

Cell proliferation assay. Cell survival was determined using CCK-8. Briefly, the logarithmic phase PaCa cells were plated in 96-well culture plates ( $7 \times 10^{3}$ cells per well). After $24 \mathrm{~h}$ of incubation, the cells were treated with the vehicle alone (0.1\% DMSO) and various concentrations (20, 40, 60, 80 and $100 \mu \mathrm{M}$ ) of oridonin, followed by 24,48 and $72 \mathrm{~h}$ of cell culture. Each group had 6 wells. A total of $10 \mu$ l CCK-8 was added to each well $1 \mathrm{~h}$ before the end of incubation. The absorbance at $450 \mathrm{~nm}$ was read using the Bio-Tek ELx800 Absorbance Microplate Reader. The experiment was repeated 3 times. The degree of cellular inhibition by each drug was calculated by the following formula: relative $\%$ inhibition $=$ 1- (dosing absorbance - blank absorbance)/(control absorbance - blank absorbance) x100\%.

Annexin V apoptosis assay. Apoptosis induction was assessed using the Annexin V-FITC kit according to the manufacturer's instructions. BxPC-3 PaCa cells were exposed to the control (DMSO-treated), the desired concentration of oridonin $(40 \mu \mathrm{M})$ and gemcitabine $(20 \mu \mathrm{M})$ alone or in combination with oridonin for $48 \mathrm{~h}$, and the floating and adherent cells were collected by centrifugation at $1,000 \mathrm{x}$ g for $5 \mathrm{~min}$. Pooled cells were washed with the binding buffer supplied by the manufacturer. Approximately $5 \times 10^{4}$ cells were suspended in $200 \mu \mathrm{l}$ of PBS, and mixed with $5 \mathrm{ml}$ of Annexin V-FITC and $10 \mathrm{ml}$ of PI. After 15 min of incubation in the dark, the fluorescence intensities of oridonin of $>10,000$ viable cells from each cell sample were analyzed by using a Coulter Epics XL flow cytometer with excitation and emission settings of 488 and $525 \mathrm{~nm}$, respectively. The data were analyzed using CellQuest software.

Cell cycle distribution by flow cytometry. The effect of oridonin on cell cycle distribution was determined by flow cytometry analysis of the DNA content in the cell nuclei following staining with PI. Asynchronized (70-80\%) confluent cells were treated with $40 \mu \mathrm{M}$ oridonin for $48 \mathrm{~h}$. The control cells were treated with $0.1 \%$ DMSO only. After incubation at $37^{\circ} \mathrm{C}$ for a specified time, the floating and adherent cells were collected by using $0.05 \%$ trypsin, washed twice with cold PBS and then fixed with ice-cold $70 \%$ ethanol overnight at $4^{\circ} \mathrm{C}$. The fixed cells were subsequently centrifuged at $300 \mathrm{x} \mathrm{g}$ for $10 \mathrm{~min}$ and the pellets were washed with PBS. The cells were then treated with $80 \mathrm{mg} / \mathrm{ml} \mathrm{RNase}$ A for $30 \mathrm{~min}$ at $37^{\circ} \mathrm{C}$. The cells were chilled over ice for $10 \mathrm{~min}$ and stained with PI $(50 \mathrm{mg} / \mathrm{ml}$ final concentration) for $1 \mathrm{~h}$ in the dark. The stained cells were analyzed using a Coulter Epics XL flow cytometer. Approximately 20,000 cells were evaluated for each experiment. In all the determinations, cell debris and clumps were excluded from the analysis. The cell cycle data were reanalyzed using ModFit software. 
Measurements of p38 and p53 mRNA by semi-quantitative RT-PCR assay. PaCa cells were treated with the assigned concentration oridonin $(40 \mu \mathrm{M})$ and gemcitabine $(20 \mu \mathrm{M})$ alone or in combination for $48 \mathrm{~h}$. The control cells were treated with $0.1 \%$ DMSO only. Subsequently, total cellular RNAs were isolated from the cells with TRIzol reagent, and the RNA content was measured using a UV spectrophotometer under $260 \mathrm{~nm}$. cDNA was synthesized with $1 \mu \mathrm{g}$ of total RNA and oligo(dT) primer according to the manufacturer's instructions. PCR amplification conditions were as follows: p38, $94^{\circ} \mathrm{C}$ $60 \mathrm{sec}, 61.8^{\circ} \mathrm{C} 60 \mathrm{sec}, 72^{\circ} \mathrm{C} 60 \mathrm{sec}, 35$ cycles; $553,94^{\circ} \mathrm{C} 45 \mathrm{sec}$, $51.9^{\circ} \mathrm{C} 1 \mathrm{~min}, 72^{\circ} \mathrm{C} 90 \mathrm{sec}, 35$ cycles; GAPDH, $94^{\circ} \mathrm{C} 45 \mathrm{sec}$, $58^{\circ} \mathrm{C} 1 \mathrm{~min}, 72^{\circ} \mathrm{C} 1 \mathrm{~min}, 35$ cycles. GAPDH was used as the internal control. The primer pairs used for the amplification are listed in Table I. The PCR product $(5 \mu \mathrm{l})$ was analyzed by $1 \%$ agarose gel electrophoresis and the results were photographed.

Western blot analysis in vitro. Briefly, $\mathrm{PaCa}$ cells were incubated with the allocated concentration of oridonin $(40 \mu \mathrm{M})$ and gemcitabine $(20 \mu \mathrm{M})$ alone or in combination for $48 \mathrm{~h}$; the cells in medium alone were used as the controls. Subsequently, the cells were harvested, washed twice with ice-cold PBS and then the cell pellets were resuspended in lysis buffer consisting of $50 \mathrm{mM}$ HEPES ( $\mathrm{pH} 7.4$ ), 1\% Triton-X 100, 2 mM sodium orthovanadate, $100 \mathrm{mM}$ sodium fluoride, $1 \mathrm{mM}$ edetic acid, $1 \mathrm{mM}$ PMSF, $10 \mathrm{mg} / \mathrm{l}$ aprotinin (Sigma), and $10 \mathrm{mg} / 1$ leupeptin (Sigma) and lysed at $4^{\circ} \mathrm{C}$ for $60 \mathrm{~min}$. After centrifugation at $13,000 \mathrm{x} \mathrm{g}$ for $15 \mathrm{~min}$, the protein content of the supernatant was determined by the bicinchoninic acid (BCA) assay kit (Sigma) according to the manufacturer's instructions. The protein lysates $(20 \mu \mathrm{g} /$ lane $)$ were separated by electrophoresis on $12 \%$ SDS polyacrylamide gel and blotted onto a nitrocellulose membrane. Each membrane was blocked with 5\% skim milk and then incubated with the indicated primary antibodies against p53, P-p53, p38, P-p38 and $\beta$-actin overnight at $4^{\circ} \mathrm{C}$. Subsequently, the membrane was incubated with the secondary antibodies, goat anti-rabbit and goat anti-mouse IgG conjugated with HRP, for $1 \mathrm{~h}$ at room temperature and the formed immunocomplex was visualized by enhanced chemiluminescence reagent and exposed to X-ray films. Quantitative data are expressed as the means \pm SD of the relative levels of the objective protein and control $\beta$-actin of each group of cells from 3 independent experiments.

Experimental animals. Female nude mice [4-6 weeks old, BALB/cA-nu (nu/nu), weight 18-20 g] were purchased from the Shanghai Cancer Institute for Tumor Implantation and maintained in a specific-pathogen-free environment at the Wenzhou Medical College Experimental Animal Center. The animals were kept in a controlled environment with a temperature of $25 \pm 1^{\circ} \mathrm{C}$ and relative humidity of $40-60 \%$. Ethical approval for this study was given by the Ethics Committee at Wenzhou Medical College.

Model establishment and experimental scheme. BxPC-3 cells in the log-phase were suspended with serum-free culture medium $\left(5 \times 10^{6}\right.$ cells in $\left.200 \mu \mathrm{l}\right)$, and tumor xenografts were established by a subcutaneous inoculation of BxPC-3 PaCa cells into the right abdominal flanks of the nude mice. Tumors were allowed to develop for 4-5 weeks until they reached a
Table I. Primer pairs used in semi-quantitative PCR analysis.

\begin{tabular}{ccc}
\hline Genes & $\begin{array}{c}\text { Primer pairs } \\
\left(5^{\prime} \rightarrow 3^{\prime}\right)\end{array}$ & $\begin{array}{c}\text { Product } \\
\text { size }(b p)\end{array}$ \\
\end{tabular}

p38

$\begin{array}{ll}\text { Sense } & \text { CGGAGTGGCATGAAGCTGTAG } \\ \text { Antisense } & \text { CCCTAGGAAACCAACACAGCA }\end{array}$

346

p53

$\begin{array}{ll}\text { Sense } & \text { TCTGGGACAGCCAAGTCTGT } \\ \text { Antisense } & \text { GGAGTCTTCCAGTGTGATGA }\end{array}$

435

GAPDH

Sense CGCTGCGCTGGTCGTCGACA

Antisense GTCACGCACGATTTCCCGCT

619

size of $100-150 \mathrm{~mm}^{3}$, and then treatment was initiated. All the mice were randomly divided into 4 groups and treated intraperitoneally (IP) with saline, gemcitabine $(80 \mathrm{mg} / \mathrm{kg})$ alone, oridonin $(40 \mathrm{mg} / \mathrm{kg})$ alone, or gemcitabine $(80 \mathrm{mg} / \mathrm{kg})$ and oridonin $(40 \mathrm{mg} / \mathrm{kg})$ in combination every 3 days for up to 30 days post-implantation in a volume of $0.2 \mathrm{ml}(\mathrm{n}=10$ per group). Tumor volume was measured using calipers and estimated according to the formula: tumor volume $\left(\mathrm{mm}^{3}\right)=$ $\mathrm{Lx} \mathrm{W}^{2} / 2$, where $\mathrm{L}$ is the length and $\mathrm{W}$ is the width. Two weeks after the last treatment, the mice were sacrificed and the tumors were excised. Xenograft tumors of the treated and control mice, were harvested and fixed in $4 \%$ formalin, embedded in paraffin, and cut into suitable sections for western blot and RT-PCR analysis.

Western blot analysis in tumor tissues. Protein was routinely extracted from tumor tissues using radioimmunoprecipitation assay (RIPA) buffer. Total protein concentration was measured using the BCA assay kit (Sigma) with bovine serum albumin as the standard, according to the manufacturer's instructions. Tumor tissue extracts containing $80 \mu \mathrm{g}$ total protein were subjected to $12 \%$ SDS/PAGE, and the resolved proteins were transferred electrophoretically to polyvinylidene fluoride (PVDF) membranes. After being blocked with 5\% fat-free milk, the membranes were probed with individual primary antibodies overnight at $4^{\circ} \mathrm{C}$ and the bound antibodies were detected with HRP-conjugated goat anti-rabbit IgG for $1 \mathrm{~h}$. The formed immunocomplex was visualized by enhanced chemiluminescence reagent (ECL; Pierce).

RT-PCR detection of p38 and p53 mRNA in tumor tissues. Total RNA was extracted from the tumor tissues using the TRIzol reagent. The amount and purity of the extracted RNA was quantified using spectrophotometry. The value of $\mathrm{A}_{260}$ / $\mathrm{A}_{280}$ was measured to evaluate the quality of the RNA. cDNA was synthesized with $5 \mu \mathrm{g}$ total RNA and oligo(dT) primer according to the manufacturer's instructions. The PCR amplification reaction was amplified using the GeneAmp PCR System 9600 (Perkin-Elmer Corp. Norwalk, CT, USA). The amplification conditions and the primer pairs used for the amplification were the same as those used for the in vitro analysis. The PCR products $(5 \mu \mathrm{l})$ were analyzed by electro- 




Chemical structure of oridonin

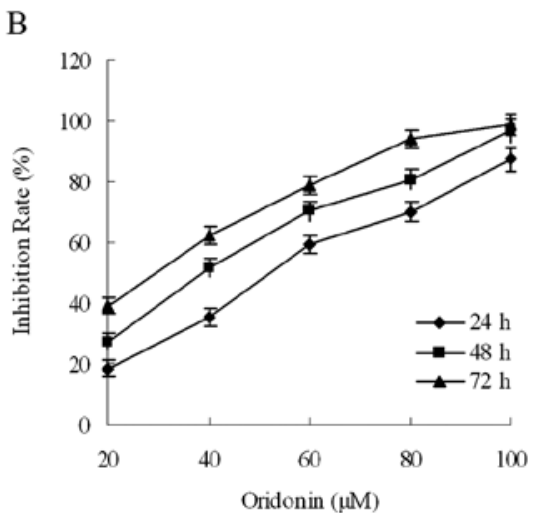

Figure 1. Effect of oridonin on inhibiting the growth of pancreatic cancer (PaCa) cells in vitro. (A) Chemical structure of oridonin. (B) BxPC-3 PaCa cells were treated with the vehicle or $20,40,60,80$ and $100 \mu \mathrm{M}$ oridonin for 24,48 or $72 \mathrm{~h}$. The cell proliferation inhibition rates were determined by the Cell Counting kit- 8 (CCK-8) assay, and they are presented as the means \pm SD from 3 independent experiments.


B

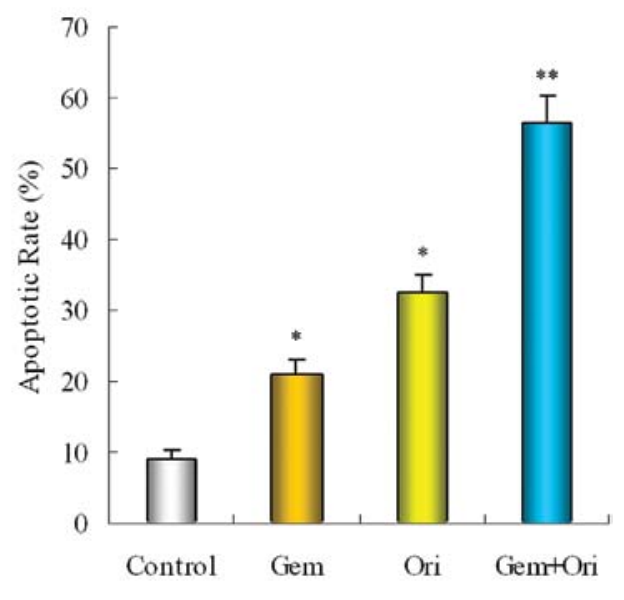

Figure 2. Effect of oridonin on apoptosis of pancreatic cancer (PaCa) cells in vitro. The BxPC-3 PaCa Cells treated with oridonin $(40 \mu \mathrm{M})$ and gemcitabine $(20 \mu \mathrm{M})$ alone or in combination for $48 \mathrm{~h}$ and apoptosis was detected by dual dye staining using Annexin V-FITC/PI. (A) Results are representative of three independent experiments. (B) The percentage of apoptotic cells is presented as the mean \pm SD of 3 independent experiments. ${ }^{*} \mathrm{P}<0.05$ and ${ }^{* *} \mathrm{P}<0.01$ vs. the control or the cells treated with gemcitabine. Gem, gemcitabine; Ori, oridonin.

phoresis on $1 \%$ agarose gel with ultraviolet (UV) illumination and the results were photographed.

Statistical analysis of the data. All results were confirmed by at least 3 separate experiments. The data are expressed as the means \pm SD. Statistical comparisons were performed by one-way ANOVA and the Student's t-test for differences between two sample means using the SPSS v17.0 software. A P-value $<0.05$ was considered to indicate statistically significant differences.

\section{Results}

The goal of the present study was to determine whether and how oridonin can be effectively used for the treatment of $\mathrm{PaCa}$ either alone or in combination with gemcitabine and if so, to clarify the mechanisms behind its therapeutic action. For this purpose, we selected the PaCa cell line, BxPC-3. In order to facilitate the imaging of the tumors in the animals, BxPC-3 cells were also used in the subcutaneous transplant model in mice.

Oridonin suppresses the proliferation and potentiates the apoptotic effects of gemcitabine in human PaCa cells in vitro. We first investigated the effect of oridonin on the proliferation of the PaCa cell line, BxPC-3. Oridonin inhibited the growth of PaCa cells (BxPC-3) in a dose- and time-dependent manner (Fig. 1). These tumor cells showed sensitivity to the oridonin treatment. The half maximal inhibitory concentration $\left(\mathrm{IC}_{50}\right)$ value of oridonin was determined as $38.86 \mu \mathrm{M}$ for the BxPC-3 cells following treatment for $48 \mathrm{~h}$. Oridonin was used at the dose of $40 \mu \mathrm{M}$.

To determine whether oridonin enhances the induction of apoptosis by gemcitabine, we investigated the occurrence of apoptosis in the cell lines. Flow cytometry analysis was performed using Annexin V-FITC/PI-stained PaCa cells. The 
A

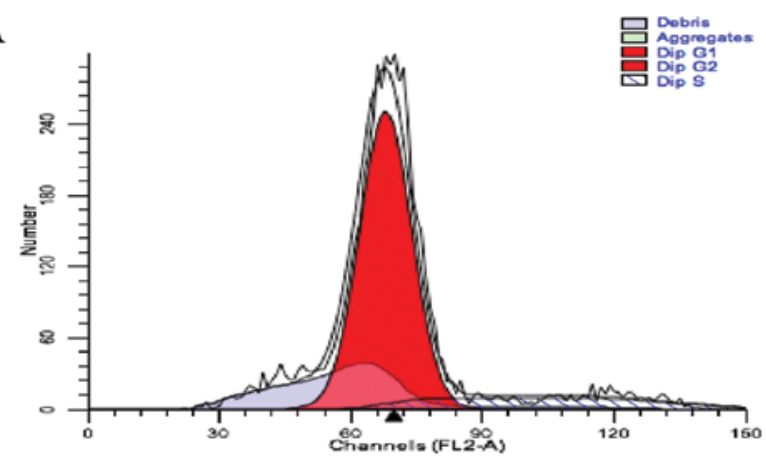

BxPC-3 Control

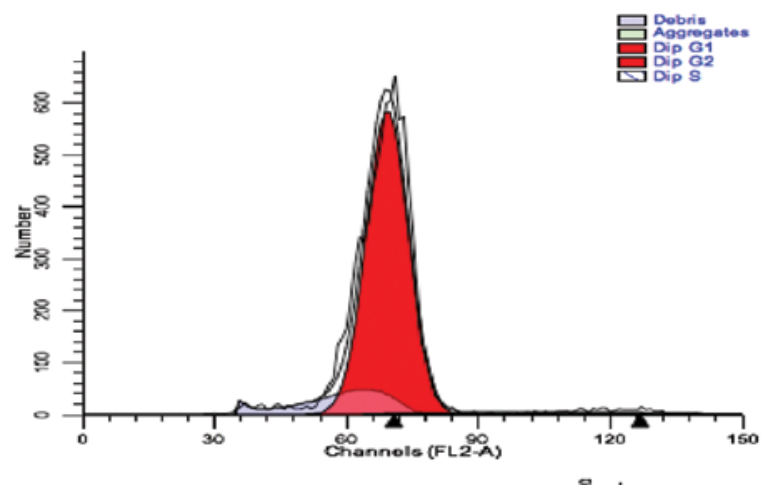

BxPC-3 Oridonin $(40 \mu \mathrm{M})$

B



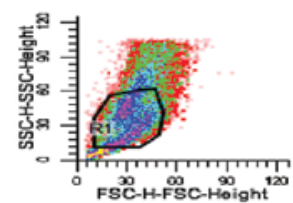

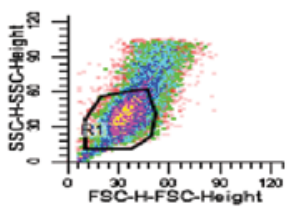

Gl
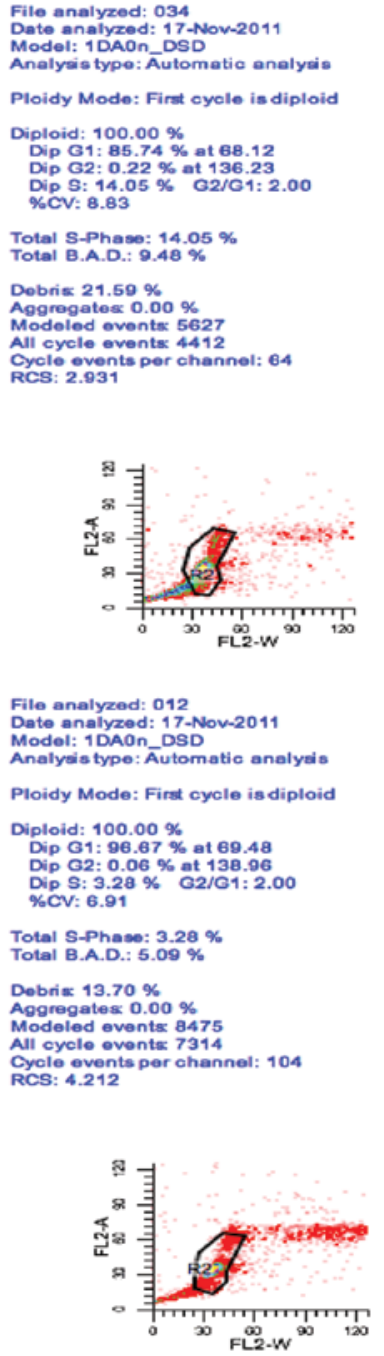

口 Control

口Oridonin

Figure 3. Effects of oridonin on cell cycle distribution of pancreatic cancer (PaCa) cells in vitro. BxPC-3 PaCa cells were treated with $40 \mu \mathrm{M}$ oridonin for $48 \mathrm{~h}$ and the control cells were treated with $0.1 \%$ DMSO only and cell cycle distribution was assessed by flow cytometry. (A) Results are representative of 3 independent experiments. (B) Cell cycle distribution determined using ModFit software version 3.1. The proportions of $\mathrm{G}_{1}, \mathrm{~S}_{\text {and }} \mathrm{G}_{2}$ phase cells are shown as indicated and presented as the means \pm SEM of 3 independent experiments. ${ }^{* *} \mathrm{P}<0.05$ vs. the control.

cells were cultured with oridonin and gemcitabine, alone or in combination for $48 \mathrm{~h}$. The results showed that, at a dose at which oridonin and gemcitabine alone were minimally effective, the combination of both was highly effective (Fig. 2).

We also investigated the mechanisms by which oridonin potentiates the effects of gemcitabine in these cells. The DNA content of the PaCa cells treated for $48 \mathrm{~h}$ with $40 \mu \mathrm{M}$ oridonin or the vehicle $(0.1 \%$ DMSO) was analyzed using a flow cytometer. Fig. 3 shows that there were marked and consistent changes in the cell cycle at $48 \mathrm{~h}$. The number of cells in the $\mathrm{G}_{1}$ phase increased significantly with a concomitant decrease in the number of treated cells in the $S$ and $G_{2}$ phase when compared with the control. These results suggest that oridonin treatment suppresses the growth of PaCa cells, and synergizes the apoptotic effects of gemcitabine.

Effect of oridonin on the gemcitabine-induced expression of $P$-p38 and P-p53 in vitro. The tumor suppressor gene product, 

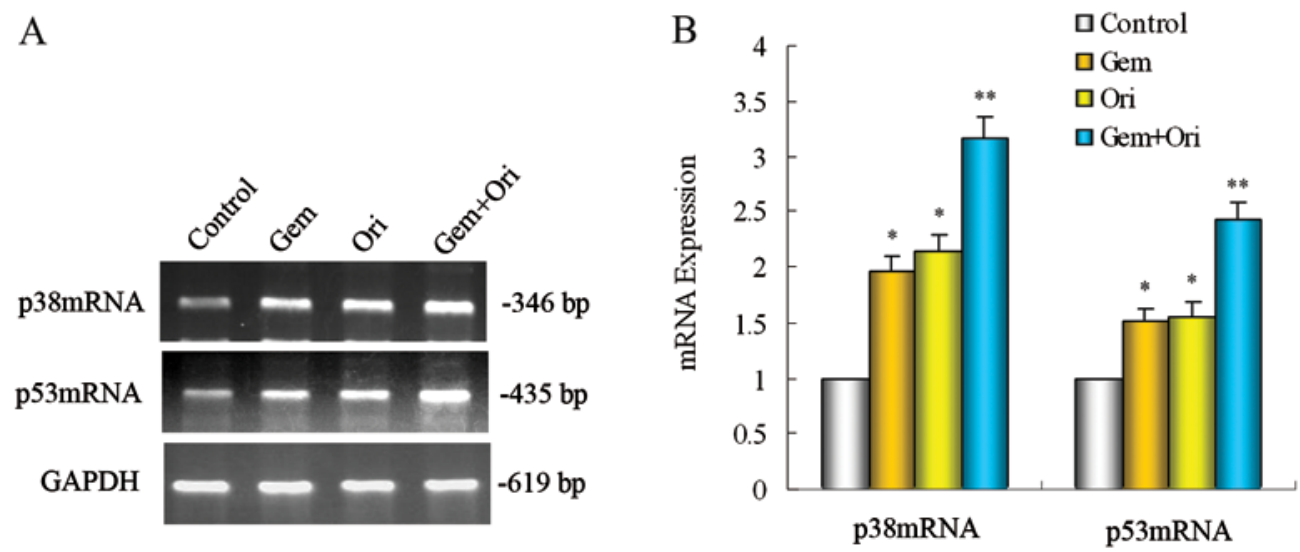

Figure 4. Effects of oridonin and gemcitabine on the mRNA expression of p38, p53 in pancreatic cancer (PaCa) cells in vitro. (A) RT-PCR analysis showed the upregulation of $\mathrm{p} 38$ and $\mathrm{p} 53 \mathrm{mRNA}$ by either oridonin alone or in combination with gemcitabine. (B) The quantification was performed assigning a value of 1 to the control group. ${ }^{*} \mathrm{P}<0.05$ vs. control; ${ }^{* *} \mathrm{P}<0.05$ vs. control or cells treated with gemcitabine alone. Gem, gemcitabine; Ori, oridonin.

A

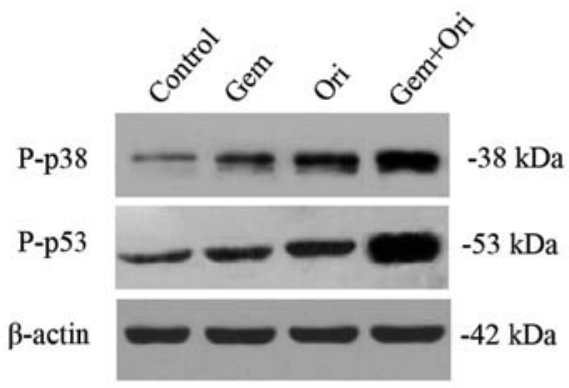

B

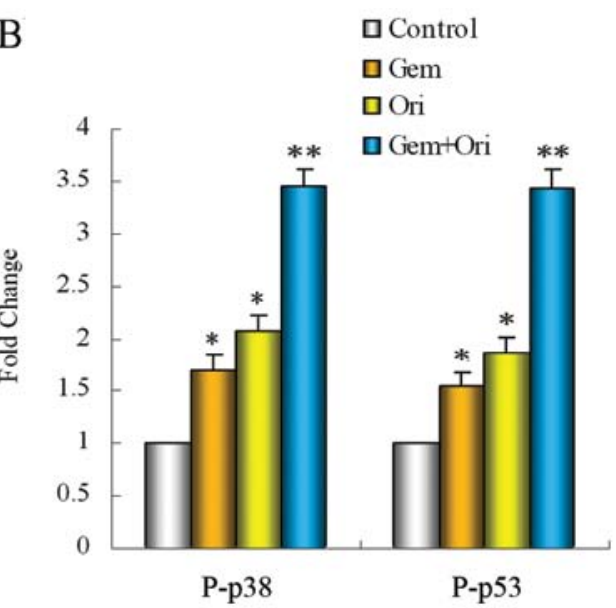

Figure 5. Oridonin potentiates the effect of gemcitabine in pancreatic cancer (PaCa) cells by activating p38, which further promotes the phosphorylation of p53 in vitro. The cells were treated with oridonin alone or in combination with gemcitabine for $48 \mathrm{~h}$. The cell lysates were then separated by $12 \%$ SDS-PAGE electrophoresis, and phosphorylated p38 (P-p38) and phosphorylated p53 (P-p53) protein expressions were detected by western blot analysis. $\mathrm{n}=3$, means \pm SD. (A) Treatment with oridonin or oridonin plus gemcitabine increased the expression of P-p38 and P-p53. (B) The relative levels of P-p38 and P-p 53 in BxPC-3 cells. The quantification was performed assigning value 1 to the control group. ${ }^{*} \mathrm{P}<0.05$ vs. controls; ${ }^{* *} \mathrm{P}<0.05$ vs. control or gemcitabine alone group. Gem, gemcitabine; Ori, oridonin.

$\mathrm{p} 53$, has been reported to mediate apoptosis in a number of experimental systems. The MAPK family members, including the extracellular signal-regulated protein kinase (ERK), c-Jun $\mathrm{N}$-terminal kinase (JNK) and p38, play important roles in the regulation of apoptosis (30). Therefore, in order to confirm whether MAPK-p38 and its downstream p53 protein are involved in the anti-cancer effects of oridonin, western blot analysis was carried out. After treatment of the $\mathrm{PaCa}$ cells with oridonin and gemcitabine alone or combination for $48 \mathrm{~h}$, the results showed that both oridonin $(\mathrm{P}<0.05)$ and gemcitabine $(\mathrm{P}<0.05)$ alone significantly increased the level of $\mathrm{P}-\mathrm{p} 38$ and P-p53 (Fig. 4), as compared with that of the control cells, and that the combination of both agents was even more effective $(\mathrm{P}<0.01)$. The unphosphorylated forms of p38 and p53 were not altered by oridonin and gemcitabine alone or combination treatment (data not shown). These results suggest that oridonin can improve the p38 activation of gemcitabine in PaCa cells, which contributes to the further activation of $\mathrm{p} 53$. This could further increase $\mathrm{PaCa}$ cell apoptosis.

Effects of oridonin and gemcitabine on p38 and p53 mRNA in PaCa cells. To further clarify whether the possible mechanism is relevant with the p38 and p53 gene, RT-PCR was carried out to detect the p38 and p53 mRNA expressions. In the PaCa cell line, BxPC-3, when compared with the control, gemcitabine alone significantly upregulated the expression of p38 and p53 mRNA $(\mathrm{P}<0.05)$. Treatment with oridonin alone or in combination with gemcitabine significantly upregulated the expression of p38 and p53 mRNA $(\mathrm{P}<0.05)$. The upregulation induced by the combined treatment of oridonin and gemcitabine was even more evident than the other groups $(\mathrm{P}<0.05)$ (Fig. 5). These results indicate that $\mathrm{p} 38$ and 553 participate in the apoptosis induced by oridonin and gemcitabine in $\mathrm{PaCa}$ cells. 


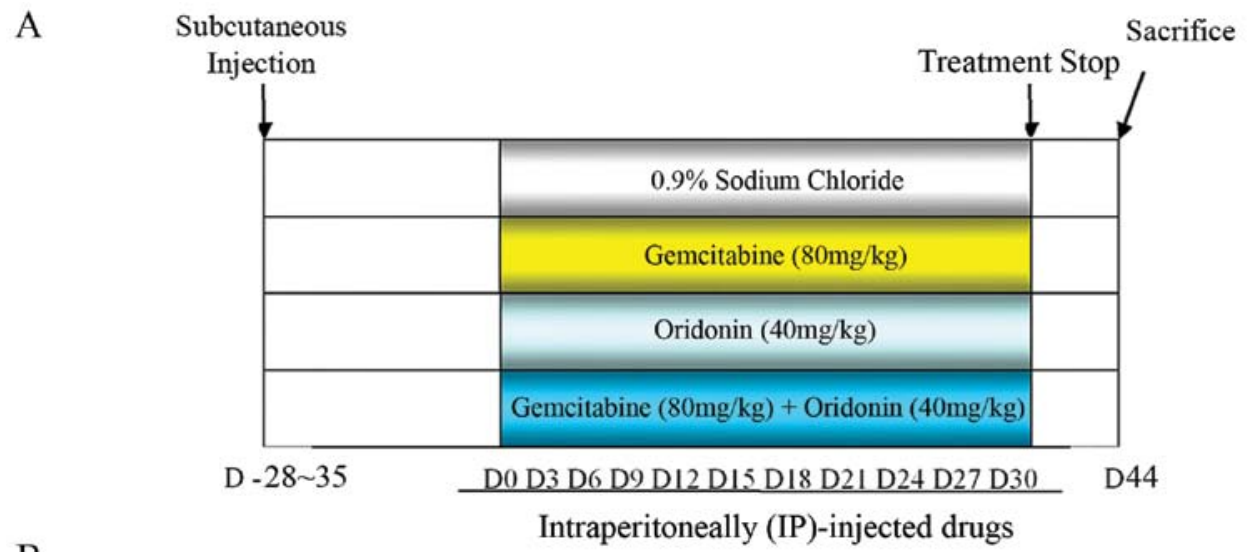

B
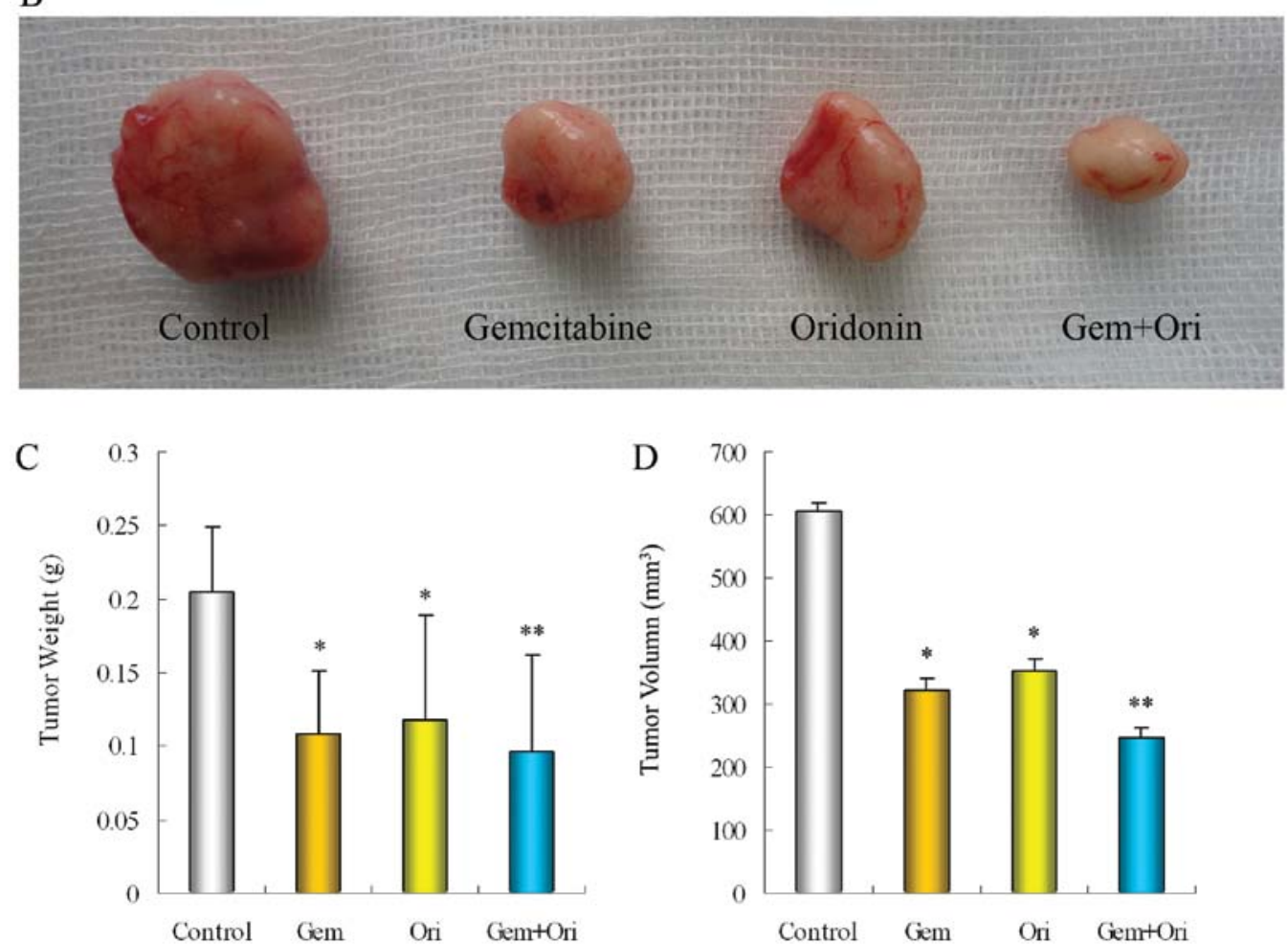

Figure 6. Oridonin enhances the effect of gemcitabine in blocking the growth of pancreatic cancer (PaCa) in nude mice. (A) The experimental protocol (B) Two weeks after the last treatment, tumors were excised from the animals, and tumor volume were measured using calipers from 10 mice. (C and D) The tumor weights and volumes of individual groups of mice. The data are representative of 3 independent experiments. ${ }^{*} \mathrm{P}<0.05$ vs. control; ${ }^{* *} \mathrm{P}<0.05$ vs. control or the group treated with a single agent. D, day; Gem, gemcitabine; Ori, oridonin.

Oridonin potentiates the anti-proliferative effects of gemcitabine in implanted $\mathrm{PaCa}$ cells in nude mice. Our in vitro data prompted us to examine whether the effects of oridonin and gemcitabine are equally demonstrable in vivo. We examined the effects of oridonin and gemcitabine, alone or in combination, on the growth of subcutaneously implanted pancreatic tumors in nude mice. The experimental protocol is depicted in Fig. 6. We found that the oral administration of oridonin alone at $40 \mathrm{mg} / \mathrm{kg}$ significantly inhibited tumor growth $(\mathrm{P}<0.05$ when compared to the control) (Fig. 6). Gemcitabine alone was as effective as oridonin $(\mathrm{P}<0.05$ when compared to the control, $\mathrm{P}>0.05$ when compared to the oridonin alone group), and the combination of both agents was even more effective in reducing the tumor burden. The tumor volume in the combination group was significantly lower than in the oridonin alone $(\mathrm{P}<0.05)$ or gemcitabine alone group $(\mathrm{P}<0.05)$ (Fig. 6).
Oridonin enhances the effect of gemcitabine via upregulating the expression of P-p38 and P-p53 in vivo. To determine whether the impact on the tumor growth inhibition of oridonin was related to the p38 and p53 activation, we evaluated the effects of oridonin and gemcitabine on P-p38 and P-p53 levels, by western blot analysis in the pancreatic tumor tissues. The results showed that both oridonin $(\mathrm{P}<0.05)$ and gemcitabine $(\mathrm{P}<0.05)$ alone significantly upregulated the expression of P-p38 and P-p53 in the PaCa tissue as compared to the control group and that the combination of both was even more effective $(\mathrm{P}<0.05$ when compared to gemcitabine alone or the control) (Fig. 7).

Effects of oridonin on expression of p38 and p53 mRNA in vivo. In order to further confirm our conclusion in pancreatic tumor tissues. we investigated the expression of p38 and p53 



Figure 7. Western blot analysis demonstrated that oridonin or gemcitabine upregulated phosphorylated p38 (P-p38) and phosphorylated p53 (P-p53) expression in tumor tissue. Two weeks after the last treatment, the protein expression of P-p38 and P-p53 was assessed by western blot analysis and quantified data are presented. (A) Treatment with oridonin or oridonin plus gemcitabine enhanced the expression of P-p38 and P-p53. (B) The relative levels of P-p38 and P-p 53 in tumor tissue. The quantification was performed assigning a value of 1 to the control group. ${ }^{*} \mathrm{P}<0.05$ vs. control; ${ }^{* *} \mathrm{P}<0.05$ vs. control or the mice treated with a single agent. Gem, gemcitabine; Ori, oridonin.
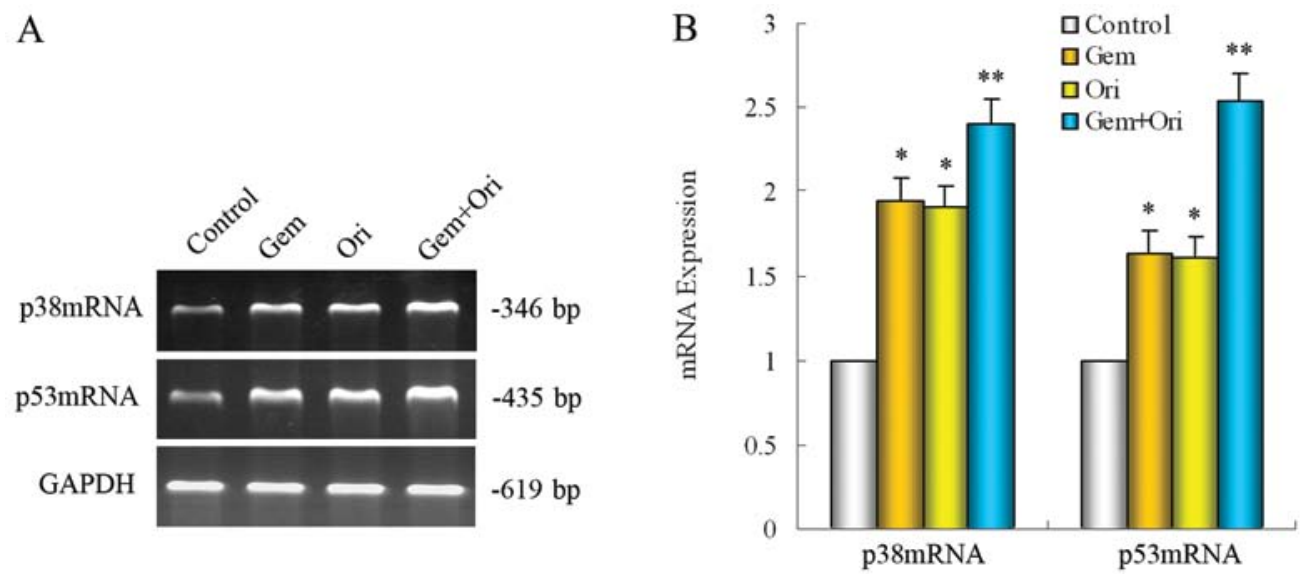

Figure 8 . The mRNA levels of p38 and p53 in tumor tissue in the different treatment groups were detected by RT-PCR and quantified data are presented (A) Oridonin alone or in combination with gemcitabine upregulated the expression of p38 and p53 mRNA. (B) The quantification was performed assigning a value of 1 to the control group. ${ }^{*} \mathrm{P}<0.05$ vs. control; ${ }^{* *} \mathrm{P}<0.05$ vs. control or the mice treated with a single agent. Gem, gemcitabine; Ori, oridonin.

mRNA levels in pancreatic tumor tissues. The results showed that oridonin either alone or in combination with gemcitabine $(\mathrm{P}<0.05$ vs. the mice treated with gemcitabine or the control) was effective in boosting the expression of p38 and p53 mRNA in PaCa tissue (Fig. 8).

\section{Discussion}

The aim of this study was to determine whether oridonin has potential either alone or in combination with gemcitabine in the treatment of $\mathrm{PaCa}$, one of the most lethal cancers. Experiments using cell cultures or an animal model, showed that oridonin alone inhibited the growth of $\mathrm{PaCa}$ and that the combination of gemcitabine and oridonin significantly enhanced this inhibition. In the PaCa cell line, BxPC-3, the data indicated that varying concentrations of oridonin effectively inhibited the proliferation of the cells at different times, and we found for the first time that oridonin enhanced the apoptotic effects of gemcitabine in cultured PaCa cells. Gemcitabine alone had a minimal effect on apoptosis in BxPC-3 cell line. However, oridonin when used in combination with gemcitabine, was highly effective in inducing apoptosis. We also found oridonin that augmented the apoptotic effects of gemcitabine, which were related to $G_{1}$ phase arrest, and the upregulation of p38 and p53. The activation of p38 and p53 could be one of the mechanisms invovled in the induction of apoptosis in PaCa cells.

In addition to these in vitro results, in a subcutaneous nude mice model, we found that oridonin effectively suppressed the growth of $\mathrm{PaCa}$. In this model, oridonin was found to be as effective as gemcitabine in inhibiting the tumor volume. When the 2 agents were used together, maximum abrogation of tumor volume was observed. Although our study is the first to report the effect of oridonin alone on $\mathrm{PaCa}$ in a mouse model, these results are consistent with those from previous reports showing the growth suppressive effects of oridonin alone against colorectal cancer (26). When we investigated the 
mechanisms by which oridonin manifests its effects against $\mathrm{PaCa}$ in an animal model, we found that this effect was also associated with the activation of p38 and p53.

MAPKs are serine/threonine kinases that mediate intracellular signaling associated with a variety of cellular activities, including cell proliferation, differentiation, survival, death and transformation $(31,32)$. The 3 main members that integrate the MAPK family in mammalian cells are stress-activated protein kinase c-Jun NH2-terminal kinase (JNK), stress-activated protein kinase 2 (SAPK2, p38) and the extracellular signal-regulated protein kinases (ERK1/2, p44/p42) (33). MAPK p38 has been shown to be activated by cellular stress, UV radiation, growth factor withdrawal and pro-inflammatory cytokines (34). Upon activation, p38 phosphorylates various transcription factors, as well as the tumor suppressor, p53 (35). A number of studies have reported the role of MAPK signaling in the regulation of apoptosis in various cancer cells $(18,19,21,36-38)$. Previous studies have documented that the activation of the p38 MAPK pathway may lead to p53-induced apoptosis (39). In human osteosarcoma cells and A431 epidermoid carcinoma cells, p38 functions as an upstream kinase of p53 phosphorylation and subsequently stabilizes and activates p53 transcriptional activity, leading to diverse cellular responses, such as cell cycle arrest and apoptosis (30). We found that in response to oridonin treatment, the increased expression of P-p38 was accompanied by the upregualtion of P-p53, which suggests that the p38 activation is involved in the $G_{1}$ cell cycle arrest and apoptosis induced by oridonin in pancreatic cells.

p53 is one of the most commonly mutated genes in human cancers and its loss of function is believed to result in increased genomic instability, with the subsequent acquisition of additional oncogenic mutations (40). The targeting of p53 is important for many cancer therapies. p53 has been shown to transactivate a broad range of pro-apoptotic proteins from the Bcl-2 family (Bax, the BH3-only proteins Bid, Puma and Noxa), and to downregulate anti-apoptotic proteins from the $\mathrm{Bcl}-2$ family (Bcl-2 and Bcl-xL), as well as to induce the upregulation of proteins that localize to the mitochondria (41). Knowledge of the p53-dependent pathway in prostate cancer could allow the development of selective and effective anticancer strategies involved with the apoptotic response (42). The phosphorylation of p53 can usually be induced at serine 15 or/and 18 . In particular, the phosphorylation of $\mathrm{p} 53$ at serine 15 has been reported to be a key phosphorylation target during the p53 activation process to apoptotic cell death (43). These data indicate that p53 may play a crucial role in oridonin-induced $\mathrm{PaCa}$ cell apoptosis.

Overall, our results suggest that oridonin has significant potential for the treatment of $\mathrm{PaCa}$ and potentiates the antitumor effects of gemcitabine by upregulating p38 and its downstream targets, leading to the inhibition of proliferation, angiogenesis and invasion. However, certain molecular links remain to be clarified, such as how the p53 signaling is connected to cell cycle arrest, and how p38 signaling acts on the p53 pathway. The specific mechanisms involved require further study. The combination of oridonin with gemcitabine has significant potential as an effective therapy for $\mathrm{PaCa}$ that can enhance the effect of gemcitabine and overcome chemoresistance. Based on these results, further clinical studies are warranted to confirm our findings in patients with $\mathrm{PaCa}$.

\section{Acknowledgements}

We are grateful for funding support from: the Administration of Traditional Chinese Medicine of Zhengjing Province, China (grant no. 2011ZZ010) and the National Natural Science Foundation of China (grant no. 81173606). We thank the entire staff of the Animal Experimental Center of Wenzhou Medical College and of the Scientific Research Platform of the Second Affiliated Hospital of Wenzhou Medical College for their invaluable assistance.

\section{References}

1. Jemal A, Siegel R, Ward E, Hao Y, Xu J, Murray T and Thun MJ: Cancer statistics, 2008. CA Cancer J Clin 58: 71-96, 2008.

2. Canadian Cancer Society/National Cancer Institute of Canada: Canadian Cancer Statistics 2008. Toronto, ISSN 0835-2976, 2008.

3. Reske SN: PET and PET-CT of malignant tumors of the exocrine pancreas. Radiologe 49: 131-136, 2009 (In German).

4. Stathis A and Moore MJ: Advanced pancreatic carcinoma: current treatment and future challenges. Nat Rev Clin Oncol 7: 163-172, 2010.

5. American Cancer Society: Cancer Facts and Figures 2007 [M]. American Cancer Society, New York, NY, 51-52, 2007.

6. Burris HA III, Moore MJ, Andersen J, et al: Improvements in survival and clinical benefit with gemcitabine as first-line therapy for patients with advanced pancreas cancer: a randomized trial. J Clin Oncol 15: 2403-2413, 1997.

7. O'Reilly EM and Abou-Alfa GK: Cytotoxic therapy for advanced pancreatic adenocarcinoma. Semin Oncol 34: 347-353, 2007.

8. O'Reilly EM: Pancreatic adenocarcinoma: new strategies for success. Gastrointest Cancer Res 3: S11-S15, 2009.

9. Tingstedt B, Johansson P, Andersson B and Andersson R: Predictive factors in pancreatic ductal adenocarcinoma: role of the inflammatory response. Scand J Gastroenterol 42: 754-759, 2007.

10. Kang SP and Saif MW: Optimal second-line treatment options for gemcitabine refractory advanced pancreatic cancer patients. Can we establish standard of care with available data? J Oral Pathol 9: 83-90, 2008

11. Kunnumakkara AB, Guha S, Krishnan S, et al: Curcumin potentiates antitumor activity of gemcitabine in an orthotopic model of pancreatic cancer through suppression of proliferation, angiogenesis, and inhibition of nuclear factor-kappaB-regulated gene products. Cancer Res 67: 3853-3861, 2007.

12. Harikumar KB, Kunnumakkara AB, Sethi G, Diagaradjane P, Anand P, Pandey MK, Gelovani J, Krishnan S, Guha S and Aggarwal BB: Resveratrol, a multitargeted agent, can enhance antitumor activity of gemcitabine in vitro and in orthotopic mouse model of human pancreatic cancer. Int J Cancer 127: 257-268, 2010.

13. Banerjee S, Kaseb AO, Wang Z, Kong D, Mohammad M, Padhye S, Sarkar FH, Mohammad RM: Antitumor activity of gemcitabine and oxaliplatin is augmented by thymoquinone in pancreatic cancer. Cancer Res 69: 5575-5583, 2009.

14. Wang ZH, Chen H, Guo HC, Tong HF, Liu JX, Wei WT, Tan W, Ni ZL, Liu HB and Lin SZ: Enhanced antitumor efficacy by the combination of emodin and gemcitabine against human pancreatic cancer cells via downregulation of the expression of XIAP in vitro and in vivo. Int J Oncol 39: 1123-1131, 2011.

15. Chen H, Wei W, Guo Y, Liu A, Tong H, Wang Z, Tan W, Liu J and Lin S: Enhanced effect of gemcitabine by emodin against pancreatic cancer in vivo via cytochrome C-regulated apoptosis. Oncol Rep 25: 1253-1261, 2011.

16. Wei WI, Chen H, Ni ZL, Liu HI, Tong HF, Fan L, Liu A, Qiu MU, Liu DL, Guo HC, Wang ZH and Lin SZ: Antitumor and apoptosis-promoting properties of emodin, an anthraquinone derivative from Rheum officinale Baill, against pancreatic cancer in mice via inhibition of Akt activation. Int J Oncol 39: 1381-1390, 2011.

17. Sun HD, Huang SX and Han QB: Diterpenoids from isodon species and their biological activities. Nat Prod Rep 23: 673-698, 2006. 
18. Huang J, Wu L, Tashiro S, Onodera S and Ikejima T: Reactive oxygen species mediate oridonin-induced HepG2 apoptosis through p53, MAPK, and mitochondrial signaling pathways. J Pharmacol Sci 107: 370-379, 2008.

19. Jin S, Shen JN, Wang J, Huang G and Zhou JG: Oridonin induced apoptosis through AKT and MAPKS signaling pathways in human osteosarcoma cells. Cancer Biol Ther 6: 261-268, 2007.

20. Liu YQ, Mu ZQ, You S, Tashiro S, Onodera S and Ikejima T: Fas/FasL signaling allows extracelluar-signal regulated kinase to regulate cytochrome $\mathrm{c}$ release in oridonin-induced apoptotic U937 cells. Biol Pharm Bull 29: 1873-1879, 2006.

21. Li D, Wu LJ, Tashiro S, Onodera S and Ikejima T: Oridonin induced A431 cell apoptosis partially through blockage of the RAS/RAF/ ERK signal pathway. J Pharmacol Sci 103: 56-66, 2007.

22. Ikezoe T, Chen SS, Tong XJ, Heber D, Taguchi H and Koeffler HP: Oridonin induces growth inhibition and apoptosis of a variety of human cancer cells. Int J Oncol 23: 1187-1193, 2003.

23. Hu HZ, Yang YB, Xu XD, Shen HW, Shu YM, Ren Z, Li XM, Shen HM and Zeng HT: Oridonin induces apoptosis via PI3K/Akt pathway in cervical carcinoma HeLa cell line. Acta Pharmacol Sin 28: 1819-1826, 2007.

24. Hsieh TC, Wijeratne EK, Liang JY, Gunatilaka AL and Wu JM: Differential control of growth, cell cycle progression, and expression of NF-kappaB in human breast cancer cells MCF-7, MCF-10A, and MDA-MB-231 by ponicidin and oridonin, diterpenoids from the chinese herb Rabdosia rubescens. Biochem Biophys Res Commun 337: 224-231, 2005.

25. Cheng Y, Qiu F, Ye YC, Tashiro S, Onodera S and Ikejima T: Oridonin induces $\mathrm{G} 2 / \mathrm{M}$ arrest and apoptosis via activating ERK-p53 apoptotic pathway and inhibiting PTK-RAS-RAFJNK survival pathway in murine fibrosarcoma L929 cells. Arch Biochem Biophys 490: 70-75, 2009.

26. Gao FH, Hu XH, Li W, Liu H, Zhang YJ, Guo ZY, Xu MH, Wang ST, Jiang B, Liu F, Zhao YZ, Fang Y, Chen FY and Wu YL: Oridonin induces apoptosis and senescence in colorectal cancer cells by increasing histone hyperacetylation and regulation of p16, p21, p27 and c-myc. BMC Cancer 10: 610, 2010.

27. Rufini A and Melino G: Cell death pathology: The war against cancer. Biochem Biophys Res Commun 414: 445-450, 2011.

28. Kim EK and Choi EJ: Pathological roles of MAPK signaling pathways in human diseases. Biochim Biophys Acta 1802: 396-405, 2010

29. Martelli AM, Nyåkern M, Tabellini G, Bortul R, Tazzari PL, Evangelisti C and Cocco L: Phosphoinositide 3-kinase/Akt signaling pathway and its therapeutical implications for human acute myeloid leukemia. Leukemia 20: 911-928, 2006.
30. Wu GS: The functional interactions between the p53 and MAPK signaling pathways. Cancer Biol Ther 3: 156-161, 2004.

31. McCubrey JA, Lahair MM and Franklin RA: Reactive oxygen species-induced activation of the MAP kinase signaling pathways. Antioxid Redox Signal 8: 1775-1789, 2006.

32. Kholodenko BN and Birtwistle MR: Four-dimensional dynamics of MAPK information processing systems. Wiley Interdiscip Rev Syst Biol Med 1: 28-44, 2009.

33. Rodríguez-Berriguete G, Fraile B, Martínez-Onsurbe P, Olmedilla G, Paniagua R and Royuela M: MAP kinases and prostate cancer. J Signal Transduct 2012: 169170, 2012.

34. Wada T and Penninger JM: Mitogen-activated protein kinases in apoptosis regulation. Oncogene 23: 2838-2849, 2004.

35. Harris SL and Levine AJ: The p53 pathway: positive and negative feedback loops. Oncogene 24: 2899-2908, 2005.

36. Shi Y, Sahu RP and Srivastava SK: Triphala inhibits both in vitro and in vivo xenograft growth of pancreatic tumor cells by inducing apoptosis. BMC Cancer 8: 294, 2008.

37. Ma Y, Yu WD, Kong RX, Trump DL and Johnson CS: Role of nongenomic activation of phosphatidylinositol 3-kinase/Akt and mitogen-activated protein kinase/extracellular signal regulated kinase kinase/extracellular signal-regulated kinase 1/2 pathway in 1,25D3-mediated apoptosis in squamous cell carcinoma cells. Cancer Res 66: 8131-8138, 2006.

38. Filomeni G, Graziani I, Rotilio G and Ciriolo MR: trans-Resveratrol induces apoptosis in human breast cancer cells MCF-7 by the activation of MAP kinases pathways. Genes Nutr 2: 295-305, 2007.

39. Bulavin DV and Fornace AJ Jr: p38 MAP kinase's emerging role as a tumor suppressor. Adv Cancer Res 92: 95-118, 2004.

40. Vousden KH and Prives C: P53 and prognosis: new insights and further complexity. Cell 120: 7-10, 2005.

41. Galluzzi L, Morselli E, Kepp O, Tajeddine N and Kroemer G: Targeting p53 to mitochondria for cancer therapy. Cell Cycle 7: 1949-1955, 2008

42. Califice S, Waltregny D, Castronovo V and van den Brûle F: Prostate carcinoma cell lines and apoptosis: a review. Rev Med Liege 59: 704-710, 2004 (In French).

43. Kim YS, Lee HJ, Jang C, Kim HS and Cho YJ: Knockdown of RCAN1.4 increases susceptibility to FAS-mediated and DNA damage-induced apoptosis by upregulation of p53 expression. Korean J Physiol Pharmacol 13: 483-489, 2009. 